Research Article

\title{
Numerical Characterizations of Topological Reductions of Covering Information Systems in Evidence Theory
}

\author{
Yan-Lan Zhang $\mathbb{D}^{1}$ and Chang-Qing $\mathbf{L i}^{2}$ \\ ${ }^{1}$ College of Computer, Minnan Normal University, Zhang'zhou, Fu'jian 363000, China \\ ${ }^{2}$ School of Mathematics and Statistics, Minnan Normal University, Zhang'zhou, Fu'jian 363000, China \\ Correspondence should be addressed to Yan-Lan Zhang; zyl_1983_2004@163.com
}

Received 14 October 2020; Revised 20 February 2021; Accepted 14 March 2021; Published 31 March 2021

Academic Editor: Gordon Huang

Copyright ( 2021 Yan-Lan Zhang and Chang-Qing Li. This is an open access article distributed under the Creative Commons Attribution License, which permits unrestricted use, distribution, and reproduction in any medium, provided the original work is properly cited.

\begin{abstract}
The reductions of covering information systems in terms of covering approximation operators are one of the most important applications of covering rough set theory. Based on the connections between the theory of topology and the covering rough set theory, two kinds of topological reductions of covering information systems are discussed in this paper, which are characterized by the belief and plausibility functions from the evidence theory. The topological spaces by two pairs of covering approximation operators in covering information systems are pseudo-discrete, which deduce partitions. Then, using plausibility function values of the sets in the partitions, the definitions of significance and relative significance of coverings are presented. Hence, topological reduction algorithms based on the evidence theory are proposed in covering information systems, and an example is adopted to illustrate the validity of the algorithms.
\end{abstract}

\section{Introduction}

The theory of rough set is a new mathematical method to deal with imprecision, vagueness, and uncertainty in data analysis [1]. The basic notions in the rough set theory are the lower and upper approximation operators. The attribute reduction of datasets in terms of the lower and upper approximation operators is one of most important applications of the rough set theory. The covering rough set is one of the most important extensions of the classical Pawlak rough sets, which has received increasing concern in recent years [2-21]. By using the covering approximation operators, attribute reductions of covering information systems may be unraveled [22-32].

The theory of topology has many applications in almost all branches of mathematics and many real life applications. The topological interior and closure operators are two basic definitions in the topological theory. The theory of topology has a close contact with the theory of rough set based on the connections between the topological interior and closure operators and the lower and upper approximation operators, and there exists much result on relationships between topology and covering rough sets [20, 33-39]. Moreover, topological reductions for three types of covering rough sets in covering information systems have been discussed [40].

The Dempster-Shafer theory of evidence or the theory of belief function [41, 42] is an important method to deal with uncertainty in information systems. The plausibility and belief functions construct a dual pair of uncertainty measures in Dempster-Shafer theory of evidence. There exist strong connections between the Dempster-Shafer theory of evidence and the rough set theory. For example, the relationships between the belief functions and covering rough sets are discussed [23, 43-45]. Furthermore, the evidence theory was used to characterize knowledge reductions for covering rough sets in covering information systems [23, 46-48].

The purpose of this paper is to characterize two types of topological reductions of covering information systems by evidence theory. In Section 2, we review basic definitions of covering rough sets, topology, and evidence theory. Properties of two pairs of covering approximation operators and 
the topologies induced by the two pairs of covering approximation operators are also presented. In Section 3, topological reductions in covering information systems are characterized by the belief and plausibility functions from the evidence theory. Using plausibility function values of the sets in the partitions, the definitions of significance and relative significance of coverings are also developed. Then, topological reduction algorithms based on the evidence theory are proposed in covering information systems, and an example is adopted to illustrate the validity of the algorithms. In Section 4, we compare a type of topological reduction with a kind of reduction proposed in [23].

\section{Preliminaries}

In this section, we introduce some basic definitions of topology, covering rough sets, and evidence theory. Throughout this paper, we always assume that the universe of discourse $U$ is a finite and nonempty set unless other statements. The class of all subsets of $U$ will be denoted by $\mathscr{P}(U)$.

2.1. Basic Concepts in Topology. In this section, some basic concepts of topological spaces are reviewed. For the other basic topological concepts, we refer to [49].

Definition 1 (see [49]). Let $U$ be a nonempty set. A topology on $U$ is a collection $\tau$ of subsets of $U$ having the following properties:

(1) $\varnothing$ and $U$ are in $\tau$

(2) The union of the elements of any subcollection of $\tau$ is in $\tau$

(3) The intersection of the elements of any finite subcollection of $\tau$ is in $\tau$

Then, $(U, \tau)$ is called a topological space, each element in $\tau$ is called an open set, and the complement of an open set is called a closed set. In a topological space $(U, \tau)$, if $A \subseteq U$ is open in $U$ and if and only if $A$ is closed in $U$, then $(U, \tau)$ is called a pseudo-discrete space.

Definition 2 (see [49]). Let $(U, \tau)$ be a topological space and $X \in \mathscr{P}(U)$. Then, the topological interior and closure of $X$ are, respectively, defined by int $_{\tau}(X)=\cup\{G \mid G$ is an open set and $G \subseteq X\}$,

$c l_{\tau}(X)=\cap\{K \mid K$ is a closed set and $X \subseteq K\}$. int $\tau_{\tau}$ and $c l_{\tau}$ are, respectively, called the topological interior operator and the topological closure operator of $\tau$.

It can be shown that $c l_{\tau}(X)$ is a closed set and int ${ }_{\tau}(X)$ is an open set in $(U, \tau) . X$ is an open set in $(U, \tau)$ if and only if int $_{\tau}(X)=X$, and $X$ is a closed set in $(U, \tau)$ if and only if $c l_{\tau}(X)=X$. The topological interior and closure operators can be also defined by Kuratowski interior and closure axioms.

Definition 3 (see $[49,50]$ ). Let $U$ be a nonempty set, int: $\mathscr{P}(U) \longrightarrow \mathscr{P}(U)$, and $c l: \mathscr{P}(U) \longrightarrow \mathscr{P}(U)$. For any $X, Y \subseteq U$,
(i1) $\operatorname{int}(U)=U$.
(i2) $\operatorname{int}(X) \subseteq X$.
(i3) $\operatorname{int}(X \cap Y)=\operatorname{int}(X) \cup \operatorname{int}(Y)$.
(i4) $\operatorname{int}(\operatorname{int}(X))=\operatorname{int}(X)$.
(c1) $c l(\varnothing)=\varnothing$.
(c2) $X \subseteq c l(X)$.
(c3) $c l(X \cup Y)=\operatorname{cl}(X) \cup \operatorname{cl}(Y)$.
(c4) $\operatorname{cl}(\mathrm{cl}(X))=\operatorname{cl}(X)$.

If int satisfies $(i 1)-(i 3)$, then int is called an interior operator, and $(U$, int) is called an interior space [50]. If int satisfies (i1)-(i4), that is, int satisfies Kuratowski interior axiom, then int is called a topological interior operator [49]. If $c l$ satisfies $(c 1)-(c 3)$, then $c l$ is called a closure operator, and $(U, c l)$ is called a closure space [50]. If $c l$ satisfies $(c 1)-(c 4)$, that is, $c l$ satisfies Kuratowski closure axiom, then $c l$ is called a topological closure operator [49].

In an interior space $(U$, int), it is easy to prove that $\tau($ int $)=\{X \mid \operatorname{int}(X)=X\}$ is a topology. In a closure space $(U, c l)$, it is easy to verify that $\tau(c l)=\{U-X \mid c l(X)=X\}$ is a topology.

2.2. Basic Definitions of Covering Rough Sets. We present definitions of two pairs of covering approximation operators.

Definition 4 (see $[7,8,18,24])$. Let $\mathscr{C}$ be a covering of the universe $U$. For any $x \in U, \quad(x)_{\mathscr{C}}=\cap\{K \in \mathscr{C} \mid x \in K\}$ is called a neighborhood of $x$ by $\mathscr{C}$. Define two pairs of covering approximation operators $\left(F L_{\mathscr{C}}, F H_{\mathscr{C}}\right)$ and $\left(L L_{\mathscr{C}}, L H_{\mathscr{C}}\right)$ as follows: $\forall X \subseteq U$,

$$
\begin{aligned}
& F L_{\mathscr{C}}(X)=\{x \mid \forall K \in \mathscr{C} x \in K \Longleftrightarrow K \subseteq X\}[7] . \\
& F H_{\mathscr{C}}(X)=\cup\{K \mid K \in \mathscr{C} K \cap X \neq \varnothing\}[18] . \\
& L L_{\mathscr{C}}(X)=\left\{x \mid \forall y \in U, x \in(y)_{\mathscr{C}} \Longleftrightarrow(y)_{\mathscr{C}} \subseteq X\right\}[8] . \\
& L H_{\mathscr{C}}(X)=\cup\left\{(x)_{\mathscr{C}} \mid(x)_{\mathscr{C}} \cap X \neq \varnothing\right\}[8,24] .
\end{aligned}
$$

The pair of covering approximation operators $\left(F L_{\mathscr{C}}, F H_{\mathscr{C}}\right)$ was discussed in $[7,18,21,51,52]$, and the pair of covering approximation operators $\left(L L_{\mathscr{C}}, L H_{\mathscr{C}}\right)$ was explored in $[8,24,53]$.

For any $x \in U$, define $\operatorname{st}(x, \mathscr{C})=\cup\{K \in \mathscr{C} \mid x \in K\}$. Then, $F L_{\mathscr{C}}(X)=\{x \in U \mid \operatorname{st}(x, \mathscr{C}) \subseteq X\}$. It is easy to obtain that for any $x, y \in U$, (1) $x \in(x)_{\mathscr{C}}$, (2) if $x \in(y)_{\mathscr{C}}$, then $(x)_{\mathscr{C}} \subseteq(y)_{\mathscr{C}}, \quad$ (3) $\quad x \in \operatorname{st}(x, \mathscr{C}), \quad$ and $x \in \operatorname{st}(y, \mathscr{C}) \Leftrightarrow y \in \operatorname{st}(x, \mathscr{C})$.

Some basic properties of the pairs of approximation operators $\left(F L_{\mathscr{C}}, F H_{\mathscr{C}}\right)$ and $\left(L L_{\mathscr{C}}, L H_{\mathscr{C}}\right)$ are presented in Proposition 1.

Proposition 1 (see $[7,18,53,54])$. Let $\mathscr{C}$ be a covering of the universe $U$. Then, for any $X, Y \subseteq U$, we get

$$
\begin{aligned}
\text { (1) } & F L_{\mathscr{C}}(\varnothing)=F H_{\mathscr{C}}(\varnothing)=\varnothing, \\
& F L_{\mathscr{C}}(U)=F H_{\mathscr{C}}(U)=U . \\
\text { (2) } & F L_{\mathscr{C}}(X \cap Y)=F L_{\mathscr{C}}(X) \cap F L_{\mathscr{C}}(Y), \\
& F H_{\mathscr{C}}(X \cup Y)=F H_{\mathscr{C}}(X) \cup F H_{\mathscr{C}}(Y) .
\end{aligned}
$$



(3) $F L_{\mathscr{C}}(X) \subseteq X \subseteq F H_{\mathscr{C}}(X)$.
(4) $F L_{\mathscr{C}}(X)=X \Leftrightarrow F H_{\mathscr{C}}(X)=X$.
(5) $F H_{\mathscr{C}}(U-X)=U-F L_{\mathscr{C}}(X)$.
(6) $L L_{\mathscr{C}}(\varnothing)=L H_{\mathscr{C}}(\varnothing)=\varnothing, L L_{\mathscr{C}}(U)=L H_{\mathscr{C}}(U)=U$.
(7) $L L_{\mathscr{C}}(X \cap Y)=L L_{\mathscr{C}}(X) \cap L L_{\mathscr{C}}(Y)$,
$L H_{\mathscr{C}}(X \cup Y)=L H_{\mathscr{C}}(X) \cup L H_{\mathscr{C}}(Y)$.
(8) $L L_{\mathscr{C}}(X) \subseteq X \subseteq L H_{\mathscr{C}}(X)$.
(9) $L L_{\mathscr{C}}(X)=X \Leftrightarrow L H_{\mathscr{C}}(X)=X$.
(10) $L H_{\mathscr{C}}(U-X)=U-L L_{\mathscr{C}}(X)$.

According to Definition 3 and Proposition 1, it is easy to get the following.

Corollary 1 (see $[40,54])$. Let $\mathscr{C}$ be a covering of the universe $U$. Then,

(1) $F L_{\mathscr{C}}$ and $L L_{\mathscr{C}}$ are interior operators.

(2) $\mathrm{FH}_{\mathscr{C}}$ and $\mathrm{LH}_{\mathscr{C}}$ are closure operators.

(3) $\tau\left(F H_{\mathscr{C}}\right)=\left\{X \mid F H_{\mathscr{C}}(U-X)=U-X\right\}=\tau\left(F L_{\mathscr{C}}\right)$, $\tau\left(L H_{\mathscr{C}}\right)=\left\{X \mid L H_{\mathscr{C}}(U-X)=U-X\right\}=\tau\left(L L_{\mathscr{C}}\right)$.

(4) $\left(U, \tau\left(F H_{\mathscr{C}}\right)\right)$ and $\left(U, \tau\left(L H_{\mathscr{C}}\right)\right)$ are pseudo-discrete spaces.

By Corollary 1, $\left(U, \tau\left(F H_{\mathscr{C}}\right)\right)$ and $\left(U, \tau\left(L H_{\mathscr{C}}\right)\right)$ are pseudo-discrete spaces; then, $\tau\left(F H_{\mathscr{C}}\right)=\left\{X \mid F H_{\mathscr{C}}(X)=X\right\}$ and $\tau\left(L H_{\mathscr{C}}\right)=\left\{X \mid L H_{\mathscr{C}}(X)=X\right\}$. There also exists a conclusion about a pseudo-discrete space.

Lemma 1 (see [40]). Let $(U, \tau)$ be a pseudo-discrete space; then, $\left\{(x)_{\tau} \mid x \in U\right\}$ is a partition of $U$.

Proof. Suppose that there exist $x, y \in U$ such that $(x)_{\tau} \cap(y)_{\tau} \neq \varnothing$ and $(x)_{\tau} \neq(y)_{\tau}$. Then, $x \notin(y)_{\tau}$ or $y \notin(x)_{\tau}$. Otherwise, $(x)_{\tau} \subseteq(y)_{\tau}$ and $(y)_{\tau} \subseteq(x)_{\tau}$, and it follows that $(x)_{\tau} \subseteq(y)_{\tau}$, which contradicts that $(x)_{\tau} \neq(y)_{\tau}$. Without loss of generality, we assume that $x \notin(y)_{\tau}$. Since $(U, \tau)$ is pseudo-discrete, $(x)_{\tau} \cap(y)_{\tau}$ is open and closed. It implies that $x \in(x)_{\tau}-\left((x)_{\tau} \cap(y)_{\tau}\right)$ and $(x)_{\tau}-\left((x)_{\tau} \cap(y)_{\tau}\right)$ is an open and closed set. Since $(x)_{\tau} \cap(y)_{\tau} \neq \varnothing, \quad(x)_{\tau}-$ $\left((x)_{\tau} \cap(y)_{\tau}\right) \subsetneq(x)_{\tau}$, which contradicts the definition of $(x)_{\tau}$. Consequently, $\left\{(x)_{\tau} \mid x \in U\right\}$ is a partition of $U$.

By Corollary 1(4) and Lemma 1, it is easy to get the following.

Corollary 2 (see [40]). Let $\mathscr{C}$ be a covering of the universe $U$. Then, $\left\{(x)_{\tau\left(F H_{\mathscr{C}}\right)} \mid x \in U\right\}$ and $\left\{(x)_{\tau\left(L H_{\mathscr{C}}\right)} \mid x \in U\right\}$ are two partitions of $U$.

2.3. Basic Notions Related to Evidence Theory. This section will recall some basic definitions about evidence theory.

Definition 5 (see [41, 42]). A set function Bel: $\mathscr{P}(U) \longrightarrow[0,1]$ is referred to as a belief function if

(1) $\operatorname{Bel}(\varnothing)=0, \operatorname{Bel}(U)=1$.

(2) For every collection of subsets $X_{1}, X_{2}, \ldots, X_{n} \subseteq U$, $n \geq 1$,
$\operatorname{Bel}\left(\cup_{i=1}^{n} X_{i}\right) \geq \sum_{\varnothing \neq I \subseteq\{1,2, \ldots, n\}}(-1)^{|I|+1} \operatorname{Bel}\left(\cap_{i \in I} X_{i}\right)$,

where $|I|$ is the cardinality of the set $I$. A set function $P l: \mathscr{P}(U) \longrightarrow[0,1]$ is referred to as a plausibility function if

(1) $P l(\varnothing)=0, P l(U)=1$.

(2) For every collection of subsets $X_{1}, X_{2}, \ldots, X_{n} \subseteq U$, $n \geq 1$,

$P l\left(\cap_{i=1}^{n} X_{i}\right) \leq \sum_{\varnothing \neq I \subseteq\{1,2, \ldots, n\}}(-1)^{|I|+1} P l\left(\cup_{i \in I} X_{i}\right)$.

Belief and plausibility functions based on the same belief structure are connected by the dual property $P l(X)=$ $1-\operatorname{Bel}(-X)$. Furthermore, $\operatorname{Bel}(X) \leq P l(X)$ for all $X \subseteq U$.

Definition 6. Let $\Omega$ be a sample space and $\mathscr{F}$ be a $\sigma$-algebra on $\Omega$. Then, a real-valued function $P: \mathscr{F} \longrightarrow[0,1]$ is referred to as a probability on $(\Omega, \mathscr{F})$ if it satisfies

(1) For any $X \in \mathscr{F}, 0 \leq P(X) \leq 1$.

(2) $P(\Omega)=1$.

(3) For any $X_{i} \in \mathscr{F}(i=1,2, \ldots)$, if $X_{i} \cap X_{j}=\varnothing(i \neq j)$, then $P\left(\cup_{i=1}^{\infty} X_{i}\right)=\sum_{i=1}^{\infty} P\left(X_{i}\right)$.

Moreover, $(\Omega, \mathscr{F}, P)$ is a probability space.

The probability of covering lower approximate operator and covering upper approximate operator are, respectively, belief and plausibility functions.

Proposition 2 (see $[44,47])$. Let $(U, \mathscr{P}(U), P)$ be a probability space and $\mathscr{C}$ be a covering on $U$. For any $A \subseteq U$, define

$$
\begin{gathered}
\operatorname{Bel}_{\mathscr{C}}^{F}(X)=P\left(F L_{\mathscr{C}}(X)\right), \\
\operatorname{Pl}_{\mathscr{C}}^{F}(X)=P\left(F H_{\mathscr{C}}(X)\right), \\
\operatorname{Bel}_{\mathscr{C}}^{L}(X)=P\left(L L_{\mathscr{C}}(X)\right), \\
P l_{\mathscr{C}}^{L}(X)=P\left(L H_{\mathscr{C}}(X)\right),
\end{gathered}
$$

where $P(X)=(|X| /|U|)$. Then, Bel $_{\mathscr{C}}^{F}$ and $B e l_{\mathscr{C}}^{L}$ are belief functions and $P l_{\mathscr{C}}^{F}$ and $P l_{\mathscr{C}}^{L}$ are plausibility functions.

\section{Evidence-Theory-Based Numerical Characterization of Topological Reductions in Covering Information Systems}

A covering on $U$ can be induced from a family of coverings $\mathbf{C}$ on $U$ as follows.

Definition 7 (see [55]). Let $\mathbf{C}$ be a family of coverings on $U$. For any $\mathbf{B}=\left\{\mathscr{C}_{1}, \mathscr{C}_{2}, \ldots, \mathscr{C}_{n}\right\} \subseteq \mathbf{C}$, define $\wedge \mathbf{B} \triangleq \mathscr{C}_{1} \wedge$ $\mathscr{C}_{2} \wedge \cdots \wedge \mathscr{C}_{n}=\left\{K_{1} \cap K_{2} \cap \cdots \cap K_{n} \neq \varnothing \mid K_{i} \in \mathscr{C}_{i}, i=1,2\right.$, $\ldots, n\}$.

It is easy to obtain that $\triangle \mathbf{B}$ is a covering of $U$. For simplicity, $F L_{\wedge \mathbf{B}}, F H_{\wedge \mathbf{B}}, L L_{\wedge \mathbf{B}}, L H_{\wedge \mathbf{B}},(x)_{\wedge \mathbf{B}}, \mathrm{Bel}_{\wedge \mathbf{B}}^{F}, P l_{\wedge \mathbf{B}}^{F}$, $B e l_{\wedge \mathbf{B}}^{L}$, and $P l_{\wedge \mathbf{B}}^{L}$ are written as $F L_{\mathbf{B}}, F H_{\mathbf{B}}, L L_{\mathbf{B}}, L H_{\mathbf{B}},(x)_{\mathbf{B}}$, $B e l_{\mathbf{B}}^{F}, P l_{\mathbf{B}}^{F}, B e l_{\mathbf{B}}^{L}$, and $P l_{\mathbf{B}}^{L}$, respectively. 
It is clear that for any $\mathbf{B}=\left\{\mathscr{C}_{1}, \mathscr{C}_{2}, \ldots, \mathscr{C}_{n}\right\} \subseteq \mathbf{C}, X \subseteq U$,

(1) $s t(x, \wedge \mathbf{B})=\operatorname{st}\left(x, \mathscr{C}_{1}\right) \cap \operatorname{st}\left(x, \mathscr{C}_{2}\right) \cap \cdots \cap \operatorname{st}\left(x, \mathscr{C}_{n}\right)$.

(2) $(x)_{\mathbf{B}}=\cap_{\mathscr{C} \in \mathbf{B}}(x)_{\mathscr{C}}$.

(3) $F L_{\mathbf{B}}(X) \subseteq F L_{\mathbf{C}}(X) \subseteq X \subseteq F H_{\mathbf{C}}(X) \subseteq F H_{\mathbf{B}}(X)$.

(4) $L L_{\mathbf{B}}(X) \subseteq L L_{\mathbf{C}}(X) \subseteq X \subseteq L H_{\mathbf{C}}(X) \subseteq L H_{\mathbf{B}}(X)$.

Remark 1. From Corollary 2, we can know that $\left\{(x)_{\tau\left(F H_{\mathrm{C}}\right)} \mid x \in U\right\}$ and $\left\{(x)_{\tau\left(L H_{\mathrm{C}}\right)} \mid x \in U\right\}$ are two partitions of $U$. We denote $\left\{(x)_{\tau\left(F H_{\mathrm{C}}\right)} \mid x \in \quad U\right\}=\left\{K_{1}, K_{2}\right.$, $\left.\ldots, K_{m}\right\}(m \in N)$ and $\left\{(x)_{\tau\left(F H_{\mathrm{C}}\right)} \mid x \in U\right\}=\left\{G_{1}, G_{2}, \ldots\right.$, $\left.G_{n}\right\}(n \in N)$. Let $\mathbf{C}$ be a family of coverings on $U$; then, $(U, \mathbf{C})$ is called a covering information system in [23]. Two kinds of reductions of covering information systems are defined as follows.

Definition 8 (see [40]). Let $(U, \mathbf{C})$ be a covering information system.

(1) For any $\mathbf{B} \subseteq \mathbf{C}$, if $\tau\left(F H_{\mathbf{B}}\right)=\tau\left(F H_{\mathbf{C}}\right)$ (or $\left.\tau\left(F L_{\mathbf{B}}\right)=\tau\left(F L_{\mathbf{C}}\right)\right)$, then $\mathbf{B}$ is called as an $F$ topological consistent set of $\mathbf{C}$. If $\mathbf{B}$ is an $F$ topological consistent set of $\mathbf{C}$ and no proper subset of $\mathbf{B}$ is an $F$ topological consistent set of $\mathbf{C}$, then $\mathbf{B}$ is referred to as an $F$ topological reduct of $\mathbf{C}$. The intersection of all $F$ topological reduct of $\mathbf{C}$ is called $F$ topological core of $\mathbf{C}$, which is denoted by $\operatorname{Core}^{F}(\mathbf{C})$.

(2) For any $\mathbf{B} \subseteq \mathbf{C}$, if $\tau\left(L H_{\mathbf{B}}\right)=\tau\left(L H_{\mathbf{C}}\right)$ (or $\left.\tau\left(L L_{\mathbf{B}}\right)=\tau\left(L L_{\mathbf{C}}\right)\right)$, then $\mathbf{B}$ is called as an $L$ topological consistent set of $\mathbf{C}$. If $\mathbf{B}$ is an $L$ topological consistent set of $\mathbf{C}$ and no proper subset of $\mathbf{B}$ is an $L$ topological consistent set of $\mathbf{C}$, then $\mathbf{B}$ is referred to as an $L$ topological reduct of $\mathbf{C}$. The intersection of all $L$ topological reduct of $\mathbf{C}$ is called $L$ topological core of $\mathbf{C}$, which is denoted by $\operatorname{Core}^{L}(\mathbf{C})$.

We employ Example 1 below to state Definition 8, which is a modified example in $[23,24]$.

Example 1. Consider the problem of evaluating credit card applicants. Let $U=\left\{x_{1}, x_{2}, \ldots, x_{5}\right\}$ be a set of five applicants and $E=\{$ education; salary; assets $\}$ be a set of three attributes, where the values of "education" are \{higher; secondary; primary\}, the values of "salary" are \{high; middle; low\}, and the values of "assets" are \{high; middle; low\}. Suppose we have three specialists $\{A, B, C\}$ to evaluate the attribute values for these applicants, and their evaluation results of the same attribute may not be the same. The results are listed below.

For the attribute "education":

A: higher $=\left\{x_{1}, x_{2}\right\}$, secondary $=\left\{x_{3}, x_{4}\right\}$, low $=\left\{x_{5}\right\}$.

B: higher $=\left\{x_{1}\right\}$, secondary $=\left\{x_{2}, x_{3}\right\}$, low $=\left\{x_{4}, x_{5}\right\}$.

$\mathrm{C}$ : higher $=\left\{x_{1}, x_{2}\right\}$, secondary $=\left\{x_{3}\right\}$, low $=\left\{x_{4}, x_{5}\right\}$.

For the attribute "salary":

A: higher $=\left\{x_{1}, x_{2}\right\}$, middle $=\left\{x_{3}, x_{4}\right\}$, low $=\left\{x_{5}\right\}$.

B: higher $=\left\{x_{1}, x_{2}, x_{3}\right\}$, middle $=\left\{x_{4}\right\}$, low $=\left\{x_{5}\right\}$.
C: higher $=\left\{x_{1}, x_{2}\right\}$, middle $=\left\{x_{3}, x_{4}\right\}$, low $=\left\{x_{5}\right\}$.

For the attribute "assets":

A: higher $=\left\{x_{1}, x_{2}\right\}$, middle $=\left\{x_{3}\right\}$, low $=\left\{x_{4}, x_{5}\right\}$.

B: higher $=\left\{x_{1}, x_{2}\right\}$, middle $=\left\{x_{3}, x_{4}\right\}$, low $=\left\{x_{5}\right\}$.

C: higher $=\left\{x_{1}, x_{2}\right\}$, middle $=\left\{x_{3}, x_{4}\right\}$, low $=\left\{x_{5}\right\}$.

Suppose that the weights of the specialists $\{A, B, C\}$ are equal. To combine the evaluations without losing information, the evaluations provided by each specialist for every attribute value should be union. Then, we obtain three coverings from the attribute set $E$ :

$$
\begin{aligned}
& \mathscr{C}_{1}=\left\{\left\{x_{1}, x_{2}\right\},\left\{x_{2}, x_{3}, x_{4}\right\},\left\{x_{4}, x_{5}\right\}\right\} . \\
& \mathscr{C}_{2}=\left\{\left\{x_{1}, x_{2}, x_{3}\right\},\left\{x_{3}, x_{4}\right\},\left\{x_{5}\right\}\right\} . \\
& \mathscr{C}_{3}=\left\{\left\{x_{1}, x_{2}\right\},\left\{x_{3}, x_{4}\right\},\left\{x_{4}, x_{5}\right\}\right\} .
\end{aligned}
$$

Let $\mathbf{C}=\left\{\mathscr{C}_{1}, \mathscr{C}_{2}, \mathscr{C}_{3}\right\}$, and hence $(U, \mathbf{C})$ is a covering information system.

(1) By Definition 7, we obtain

$$
\begin{aligned}
& \mathscr{C}_{1} \wedge \mathscr{C}_{2}=\left\{\left\{x_{1}, x_{2}\right\},\left\{x_{2}, x_{3}\right\},\left\{x_{3}, x_{4}\right\},\left\{x_{4}\right\},\left\{x_{5}\right\}\right\} . \\
& \mathscr{C}_{1} \wedge \mathscr{C}_{3}=\left\{\left\{x_{1}, x_{2}\right\},\left\{x_{2}\right\},\left\{x_{3}, x_{4}\right\},\left\{x_{4}\right\},\left\{x_{4}, x_{5}\right\}\right\} . \\
& \mathscr{C}_{2} \wedge \mathscr{C}_{3}=\left\{\left\{x_{1}, x_{2}\right\},\left\{x_{3}\right\},\left\{x_{3}, x_{4}\right\},\left\{x_{4}\right\},\left\{x_{5}\right\}\right\} . \\
& \wedge \mathbf{C}=\mathscr{C}_{1} \wedge \mathscr{C}_{2} \wedge \mathscr{C}_{3}=\left\{\left\{x_{1}, x_{2}\right\},\left\{x_{2}\right\},\left\{x_{3}\right\},\left\{x_{3},\right.\right. \\
& \left.\left.x_{4}\right\},\left\{x_{4}\right\},\left\{x_{5}\right\}\right\} .
\end{aligned}
$$

We can see that $\left\{x_{1}, x_{2}\right\}$ in $\mathscr{C}_{1} \wedge \mathscr{C}_{2}$ is the set of applicants, whose education is higher and salary is higher. The other sets in $\mathscr{C}_{1} \wedge \mathscr{C}_{2}, \mathscr{C}_{1} \wedge \mathscr{C}_{3}, \mathscr{C}_{2} \wedge \mathscr{C}_{3}, \wedge \mathrm{C}$ have the same meanings.

By Definition 4 and Corollary 1, $\tau\left(F H_{\mathrm{C}}\right)=\left\{\varnothing\left\{x_{1}, x_{2}\right\}\left\{x_{5}\right\},\left\{x_{1}, x_{2}, x_{5}\right\},\left\{x_{3}, x_{4}, x_{5}\right\}\right.$, $\left.\left\{x_{1}, x_{2}, x_{3}, x_{4}\right\} U\right\}$. Thus, $\left(x_{1}\right)_{\tau\left(F H_{\mathrm{C}}\right)}=\left(x_{2}\right)_{\tau\left(F H_{\mathrm{C}}\right)}=$ $\left\{x_{1}, x_{2}\right\}, \quad\left(x_{3}\right)_{\tau\left(F H_{\mathrm{C}}\right)}=\left(x_{4}\right)_{\tau\left(F H_{\mathrm{C}}\right)}=\left\{x_{3}, x_{4}\right\}, \quad\left(x_{5}\right)_{\tau}$ $\left(F H_{C}\right)=\left\{x_{5}\right\}$, that is, the partition induced by $\tau\left(F H_{\mathrm{C}}\right)$ is $\left\{K_{1}=\left\{x_{1}, x_{2}\right\}, K_{2}=\left\{x_{3}, x_{4}\right\}, K_{3}=\left\{x_{5}\right\}\right\}$. According to Definition 8 , the $F$ topological reduct of $\mathrm{C}$ is $\left\{\mathscr{C}_{2}, \mathscr{C}_{3}\right\}$.

(2) The neighborhoods of elements are presented in Table 1. $\left(x_{1}\right)_{\left\{\mathscr{C}_{1}, \mathscr{C}_{2}\right\}}$ contains the elements whose values of "education" and "salary" are the same with $x_{1}$. The other neighborhoods of elements have the same meanings.

By Definition 4 and Corollary $1, \tau\left(L H_{\mathrm{C}}\right)=\left\{\varnothing,\left\{x_{1}, x_{2}\right\}\right.$, $\left\{x_{3}\right\}, \quad\left\{x_{4}\right\},\left\{x_{5}\right\}, \quad\left\{x_{1}, x_{2}, x_{3}\right\},\left\{x_{1}, x_{2}, x_{4}\right\}, \quad\left\{x_{1}, x_{2}, x_{5}\right\}$, $\left\{x_{3}, x_{4}\right\},\left\{x_{3}, x_{5}\right\},\left\{x_{4}, x_{5}\right\},\left\{x_{1}, x_{2}, x_{3}, x_{4}\right\},\left\{x_{1}, x_{2}, x_{3}, x_{5}\right\}$, $\left.\left\{x_{1}, x_{2}, x_{4}, x_{5}\right\},\left\{x_{3}, x_{4}, x_{5}\right\}, U\right\}$. It follows that $\left(x_{1}\right)_{\tau\left(L H_{\mathrm{C}}\right)}=$ $\left(x_{2}\right)_{\tau\left(L H_{\mathrm{C}}\right)}=\left\{x_{1}, x_{2}\right\}, \quad\left(x_{3}\right)_{\tau\left(L H_{\mathrm{C}}\right)}=\left\{x_{3}\right\}, \quad\left(x_{4}\right)_{\tau\left(L H_{\mathrm{C}}\right)}=\left\{x_{4}\right\}$, $\left(x_{5}\right)_{\tau\left(L H_{\mathrm{C}}\right)}=\left\{x_{5}\right\}$. Thus, the partition induced for $\tau\left(L H_{\mathrm{C}}\right)$ is $\left\{G_{1}=\left\{x_{1}, x_{2}\right\}, G_{2}=\left\{x_{3}\right\}, G_{3}=\left\{x_{4}\right\}, G_{4}=\left\{x_{5}\right\}\right\}$. According to Definition 8 , the $L$ topological reducts of $\mathbf{C}$ are $\left\{\mathscr{C}_{1}, \mathscr{C}_{2}\right\}$ and $\left\{\mathscr{C}_{2}, \mathscr{C}_{3}\right\}$.

Theorem 1 (see [40]). Let $(U, C)$ be a covering information system, $\mathbf{B} \subseteq \mathbf{C}$.

(1) The following are equivalent: 
TABle 1: The neighborhoods of elements in Example 1.

\begin{tabular}{lccccc}
\hline$x$ & $x_{1}$ & $x_{2}$ & $x_{3}$ & $x_{4}$ & $x_{5}$ \\
\hline$(x)_{\mathscr{C}_{1}}$ & $\left\{x_{1}, x_{2}\right\}$ & $\left\{x_{2}\right\}$ & $\left\{x_{2}, x_{3}, x_{4}\right\}$ & $\left\{x_{4}\right\}$ & $\left\{x_{4}, x_{5}\right\}$ \\
$(x)_{\mathscr{C}_{2}}$ & $\left\{x_{1}, x_{2}, x_{3}\right\}$ & $\left\{x_{1}, x_{2}, x_{3}\right\}$ & $\left\{x_{3}\right\}$ & $\left\{x_{3}, x_{4}\right\}$ & $\left\{x_{5}\right\}$ \\
$(x)_{\mathscr{C}_{3}}$ & $\left\{x_{1}, x_{2}\right\}$ & $\left\{x_{1}, x_{2}\right\}$ & $\left\{x_{3}, x_{4}\right\}$ & $\left\{x_{4}\right\}$ & $\left\{x_{4}, x_{5}\right\}$ \\
$(x)_{\left\{\mathscr{C}_{1}, \mathscr{C}_{2}\right\}}$ & $\left\{x_{1}, x_{2}\right\}$ & $\left\{x_{2}\right\}$ & $\left\{x_{3}\right\}$ & $\left\{x_{4}\right\}$ & $\left\{x_{5}\right\}$ \\
$\left.(x)_{\left\{\mathscr{C}_{1}, \mathscr{C}_{3}\right\}}\right\}$ & $\left\{x_{1}, x_{2}\right\}$ & $\left\{x_{2}\right\}$ & $\left\{x_{3}, x_{4}\right\}$ & $\left\{x_{4}\right\}$ & $\left\{x_{4}, x_{5}\right\}$ \\
$(x)_{\left\{\mathscr{C}_{2}, \mathscr{C}_{3}\right\}}\left\{x_{1}, x_{2}\right\}$ & $\left\{x_{1}, x_{2}\right\}$ & $\left\{x_{3}\right\}$ & $\left\{x_{4}\right\}$ & $\left\{x_{5}\right\}$ \\
$(x)_{\mathrm{C}}$ & $\left\{x_{1}, x_{2}\right\}$ & $\left\{x_{2}\right\}$ & $\left\{x_{3}\right\}$ & $\left\{x_{4}\right\}$ & $\left\{x_{5}\right\}$ \\
\hline
\end{tabular}

(1a) $\mathbf{B}$ is an F topological consistent set.

(1b) $F H_{\mathbf{B}}\left(K_{i}\right)=K_{i}$ for all $i \in\{1,2, \ldots, m\}$.

(1c) $F L_{\mathbf{B}}\left(K_{i}\right)=K_{i}$ for all $i \in\{1,2, \ldots, m\}$.

(2) The following are equivalent:

(2a) $\mathbf{B}$ is an L topological consistent set.

(2b) $L H_{\mathbf{B}}\left(G_{j}\right)=G_{j}$ for all $j \in\{1,2, \ldots, n\}$.

(2c) $L L_{\mathbf{B}}\left(G_{j}\right)=G_{j}$ for all $j \in\{1,2, \ldots, n\}$.

Proof. (1). (1a) $\Longleftrightarrow(1 \mathrm{~b})$. B is an $F$ topological consistent set; then, $\tau\left(F H_{\mathbf{B}}\right)=\tau\left(F H_{\mathbf{C}}\right)$. It follows that for any $x \in U$, $(x)_{\tau\left(F H_{\mathrm{B}}\right)}=(x)_{\tau\left(F H_{\mathrm{C}}\right)}$. By Corollary 1, $\left(U, \tau\left(F H_{\mathbf{B}}\right)\right)$ is pseudo-discrete. Then, $(x)_{\tau\left(F H_{\mathrm{B}}\right)}$ is a closed set in $\left(U, \tau\left(F H_{\mathbf{C}}\right)\right)$, which implies that $F H_{\mathbf{B}}\left((x)_{\tau\left(F H_{\mathrm{C}}\right)}\right)=$ $(x)_{\tau\left(F H_{\mathrm{C}}\right)}$. That is, $F H_{\mathbf{B}}\left(K_{i}\right)=K_{i}$ for all $i \in\{1,2, \ldots, m\} .(1 \mathrm{~b})$ $\Leftrightarrow$ (1c). By Proposition $1(4), F H_{\mathbf{B}}\left(K_{i}\right)=K_{i} \Leftrightarrow F L_{\mathbf{B}}\left(K_{i}\right)=$ $K_{i}$ for all $i \in\{1,2, \ldots, m\}$.(1b) $\Longleftrightarrow$ (1a). For any $A \in \tau\left(F H_{\mathbf{B}}\right), \quad F H_{\mathbf{B}}(A)=A$. By Proposition 1, $A \subseteq F H_{\mathbf{C}}(A) \subseteq F H_{\mathbf{B}}(A)$. It follows that $F H_{\mathbf{C}}(A)=A$. Then, $A \in \tau\left(F H_{\mathbf{C}}\right)$. It implies that $\tau\left(F H_{\mathbf{B}}\right) \subseteq \tau\left(F H_{\mathbf{C}}\right)$. Conversely, for any $A \in \tau\left(F H_{\mathrm{C}}\right), A=\cup_{x \in A}(x)_{\tau\left(F H_{\mathrm{C}}\right)}$. Then, $F H_{\mathrm{B}}(A)=$ $\left.F H_{\mathbf{B}}\left(\cup_{x \in A} \quad(x)_{\tau\left(F H_{\mathrm{C}}\right)}\right)=\cup_{x \in A} F H_{\mathbf{B}}\left((x)_{\tau\left(F H_{\mathbf{C}}\right)}\right)\right)=$ $\cup_{x \in A}(x)_{\tau\left(F H_{\mathrm{C}}\right)}=A$. Thus, $A \in \tau\left(F H_{\mathbf{B}}\right)$. Consequently, $\tau\left(F H_{\mathrm{C}}\right) \subseteq \tau\left(F H_{\mathrm{B}}\right)$.

Theorem 2. Let $(U, C)$ be a covering information system, $\mathbf{B} \subseteq \mathbf{C}$.

(1) The following are equivalent:

(1a) $\mathbf{B}$ is an F topological consistent set.

(1b) $\sum_{i=1}^{m} P l_{\mathbf{B}}^{F}\left(K_{i}\right)=1$.

(1c) $\sum_{i=1}^{m} \operatorname{Bel}_{\mathbf{B}}^{F}\left(K_{i}\right)=1$.

(2) The following are equivalent:

(2a) $\mathbf{B}$ is an L topological consistent set.

(2b) $\sum_{j=1}^{n} P l_{\mathbf{B}}^{L}\left(G_{j}\right)=1$.

(2c) $\sum_{j=1}^{N} \operatorname{Bel}_{\mathbf{B}}^{L}\left(G_{j}\right)=1$.

Proof. (1) (1a) $\Rightarrow$ (1b). Since $\mathbf{B}$ is an $F$ topological consistent set, by Theorem $1, F H_{\mathbf{B}}\left(K_{i}\right)=K_{i}$ for all $i \in\{1,2, \ldots, m\}$. Then,

$$
\begin{aligned}
\sum_{i=1}^{m} P l_{\mathbf{B}}^{F}\left(K_{i}\right) & =\sum_{i=1}^{m} P\left(F H_{\mathbf{B}}\left(K_{i}\right)\right) \\
& =\sum_{i=1}^{m} P\left(K_{i}\right)=P\left(\cup_{i=1}^{m} K_{i}\right)=P(U)=1 .
\end{aligned}
$$

$(1 \mathrm{~b}) \Rightarrow(1 \mathrm{c})$. For any $i \in\{1,2, \ldots, m\}, K_{i} \subseteq F H_{\mathbf{B}}\left(K_{i}\right)$. According to Definition 6 and Proposition 2,

$$
\begin{aligned}
1 & =\sum_{i=1}^{m} P l_{\mathbf{B}}^{F}\left(K_{i}\right)=\sum_{i=1}^{m} P\left(F H_{\mathbf{B}}\left(K_{i}\right)\right) \\
& \geq \sum_{i=1}^{m} P\left(K_{i}\right)=P\left(\cup_{i=1}^{m} K_{i}\right)=P(U)=1 .
\end{aligned}
$$

Since $P\left(K_{i}\right) \leq P\left(F H_{\mathbf{B}}\left(K_{i}\right)\right)$ for all $i \in\{1,2, \ldots, m\}$, we get $P\left(K_{i}\right)=P\left(F H_{\mathbf{B}}\left(K_{i}\right)\right)$, that is, $P\left(K_{i}\right)=\left(\left|K_{i}\right| /|U|\right)=\left(\left(\left|F H_{\mathbf{B}}\left(K_{i}\right)\right|\right) /|U|\right)=P\left(F H_{\mathbf{B}}\right.$ $\left(K_{i}\right)$ ). Then, for any $i \in\{1,2, \ldots, m\}, \quad\left|K_{i}\right|=$ $\left|F H_{\mathbf{B}}\left(K_{i}\right)\right|$. Since $K_{i} \subseteq F H_{\mathbf{B}}\left(K_{i}\right), K_{i}=F H_{\mathbf{B}}\left(K_{i}\right)$. By Proposition 1 (4), $K_{i}=F L_{\mathbf{B}}\left(K_{i}\right)$. Hence,

$$
\begin{aligned}
\sum_{i=1}^{m} \operatorname{Bel}_{\mathbf{B}}^{F}\left(K_{i}\right) & =\sum_{i=1}^{m} P\left(F L_{\mathbf{B}}\left(K_{i}\right)\right) \\
& =\sum_{i=1}^{m} P\left(K_{i}\right)=P\left(\cup_{i=1}^{m} K_{i}\right)=P(U)=1 .
\end{aligned}
$$

$(1 \mathrm{c}) \Rightarrow(1 \mathrm{a})$. For any $i \in\{1,2, \ldots, m\}, F L_{\mathbf{B}}\left(K_{i}\right) \subseteq K_{i}$. By Definition 2 and Proposition 2,

$$
\begin{aligned}
1 & =\sum_{i=1}^{m} \operatorname{Bel}_{\mathbf{B}}^{F}\left(K_{i}\right)=\sum_{i=1}^{m} P\left(F L_{\mathbf{B}}\left(K_{i}\right)\right) \\
& \leq \sum_{i=1}^{m} P\left(K_{i}\right)=P\left(\cup_{i=1}^{m} K_{i}\right)=P(U)=1 .
\end{aligned}
$$

Since $P\left(F L_{\mathbf{B}}\left(K_{i}\right)\right) \leq P\left(K_{i}\right)$ for all $i \in\{1,2, \ldots, m\}$, we get $P\left(K_{i}\right)=P\left(F L_{\mathbf{B}}\left(K_{i}\right)\right)$, that is, $P\left(K_{i}\right)=$ $\left(\left|K_{i}\right| /|U|\right)=\left(\left(\left|F L_{\mathbf{B}}\left(K_{i}\right)\right|\right) / \quad|U|\right)=P\left(F L_{\mathbf{B}}\left(K_{i}\right)\right)$. Then, for any $i \in\{1,2, \ldots, m\},\left|K_{i}\right|=\left|F L_{\mathbf{B}}\left(K_{i}\right)\right|$. It follows from $F L_{\mathbf{B}}\left(K_{i}\right) \subseteq K_{i}$ that $F L_{\mathbf{B}}\left(K_{i}\right)=K_{i}$. Therefore, according to Theorem $1, \mathbf{B}$ is an $F$ topological consistent set.

(2) It is similar to the proof of (1).

Theorem 3. Let $(U, C)$ be a covering information system, $\mathbf{B} \subseteq \mathbf{C}$.

(1) The following are equivalent:

(1a) $\mathbf{B}$ is an $F$ topological reduct.

(1b) $\sum_{i=1}^{m} P l_{\mathbf{B}}^{F}\left(K_{i}\right)=1$, and for any nonempty subset $\mathbf{B}^{\prime} \subset \mathbf{B}, \sum_{i=1}^{m} P l_{\mathbf{B}}^{F}\left(K_{i}\right)>1$.

(1c) $\sum_{i=1}^{m} \operatorname{Bel}_{\mathbf{B}}^{F}\left(K_{i}\right)=1$, and for any nonempty subset $\mathbf{B}^{\prime} \subset \mathbf{B}, \sum_{i=1}^{m} \operatorname{Bel}_{\mathbf{B}^{\prime}}^{F}\left(K_{i}\right)<1$.

(2) The following are equivalent:

(2a) $\mathbf{B}$ is an L topological reduct.

(2b) $\sum_{j=1}^{n} P l_{\mathbf{B}}^{L}\left(G_{j}\right)=1$, and for any nonempty proper subset $\mathbf{B}^{\prime} \subset \mathbf{A}, \sum_{j=1}^{n} P l_{\mathbf{B}^{\prime}}^{L}\left(G_{j}\right)>1$.

(2c) $\sum_{j=1}^{n} \operatorname{Bel}_{\mathbf{B}}^{L}\left(G_{j}\right)=1$, and for any nonempty proper subset $\mathbf{B}^{\prime} \subset \mathbf{A}, \sum_{j=1}^{n} \operatorname{Bel}_{\mathbf{B}}^{L}\left(G_{j}\right)<1$. 
(1) Let $\operatorname{Core}^{F}(\mathbf{C})=\varnothing, \sum_{i=1}^{m} P l_{\varnothing}^{F}\left(K_{i}\right)=m$;

(2) For each $\mathscr{C} \in \mathbf{C}$, calculate $\operatorname{Sig}_{\mathrm{C}}^{F}(\mathscr{C})=\sum_{i=1}^{m} p l_{\mathrm{C} \backslash\{\mathscr{C}\}}^{F}\left(K_{i}\right)-\sum_{i=1}^{m} p l_{\mathrm{C}}^{F}\left(K_{i}\right)$;

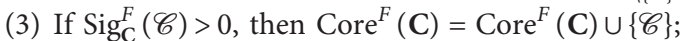

(4) If $\operatorname{Core}^{F}(\mathbf{C})=\varnothing$, then go to step (6), else go to step (5);

(5) If $\sum_{i=1}^{m} p l_{\mathrm{Core}^{F}(\mathbf{C})}^{F}\left(K_{i}\right)=1$, return $\operatorname{Core}^{F}(\mathbf{C})$ as a reduct, else go to step (6);

(6) Let $\mathbf{B}=\operatorname{Core}^{F}(\mathbf{C})$;

(7) For each $\mathscr{C} \in \mathbf{C} / \mathbf{B}$, calculate $\operatorname{Sig}_{\mathbf{B}}^{F}(\mathscr{C})=\sum_{i=1}^{m} p l_{\mathbf{B}}^{F}\left(K_{i}\right)-\sum_{i=1}^{m} p l_{\mathbf{B} \cup\{\mathbf{C}\}}^{F}\left(K_{i}\right)$;

(8) If $\operatorname{Sig}_{B}^{F}\left(\mathscr{C}_{0}\right)=\max _{\mathscr{C} \in C \backslash B} \operatorname{Sig}_{B}^{F}(\mathscr{C})$, then $\mathbf{B}=\mathbf{B} \cup\left\{\mathscr{C}_{0}\right\}$;

(9) If $\sum_{i=1}^{m} p l_{\mathbf{B}}^{F}\left(K_{i}\right)=1$, stop and output $\mathbf{B}$ as a reduct, else go to step (7).

Algorithm 1: Computing the $F$ topological core and $F$ topological reduct of $(U, \mathbf{C})$.

(1) Let $\operatorname{Core}^{L}(\mathbf{C})=\varnothing, \sum_{j=1}^{n} p l_{\varnothing}^{L}\left(G_{j}\right)=n$;

(2) For each $\mathscr{C} \in \mathbf{C}$, calculate $\operatorname{Sig}_{\mathbf{C}}^{L}(\mathscr{C})=\sum_{j=1}^{n} p l_{\mathbf{C}\{\mathscr{C}\}}^{L}\left(G_{j}\right)-\sum_{j=1}^{n} p l_{\mathbf{C}}^{L}\left(G_{i}\right)$;

(3) If $\operatorname{Sig}_{\mathrm{C}}^{L}(\mathscr{C})>0$, then $\operatorname{Core}^{L}(\mathbf{C})=\operatorname{Core}^{L}(\mathbf{C}) \cup\{\mathscr{C}\}$;

(4) If $\operatorname{Core}^{L}(\mathbf{C})=\varnothing$, then go to step (6), else go to step (5);

(5) If $\sum_{j=1}^{n} p l_{\operatorname{Core}^{L}(\mathbf{C})}^{L}\left(G_{j}\right)=1$, return $\operatorname{Core}^{L}(\mathbf{C})$ as a reduct, else go to step (6);

(6) Let $\mathbf{B}=\operatorname{Core}^{L}(\mathbf{C})$;

(7) For each $\mathscr{C} \in \mathbf{C} \backslash \mathbf{B}$, calculate $\operatorname{Sig}_{\mathbf{B}}^{L}(\mathscr{C})=\sum_{j=1}^{n} p l_{\mathbf{B}}^{L}\left(G_{j}\right)-\sum_{j=1}^{n} p l_{\mathbf{B} \backslash\{\mathbf{C}\}}^{L}\left(G_{j}\right)$;

(8) If $\operatorname{Sig}_{\mathbf{B}}^{L}\left(\mathscr{C}_{0}\right)=\max _{\mathscr{C} \in C \backslash B} \operatorname{Sig}_{B}^{L}(\mathscr{C})$, then $\mathbf{B}=\mathbf{B} \cup\left\{\mathscr{C}_{0}\right\}$;

(9) If $\sum_{j=1}^{n} P l_{\mathbf{B}}^{L}\left(G_{j}\right)=1$, stop and output $\mathbf{B}$ as a reduct, else go to step (7).

Algorithm 2: Computing the $L$ topological core and $L$ topological reduct of $(U, \mathbf{C})$.

Proof. It is immediately obtained from Theorem 2 and Definition 8.

3.1. Algorithms for Computing Topological Reducts of a Covering Information System. To give algorithms for finding topological reducts, we define the significance of a covering in a covering information system.

Definition 9. Let $(U, C)$ be a covering information system. Define the $F$ significance of the covering $\mathscr{C} \in \mathbf{C}$ by

$$
\operatorname{Sig}_{\mathbf{C}}^{F}(\mathscr{C})=\sum_{i=1}^{m} P l_{\mathbf{C} \backslash\{\mathscr{C}\}}^{F}\left(K_{i}\right)-\sum_{i=1}^{m} P l_{\mathbf{C}}^{F}\left(K_{i}\right) \text {. }
$$

Define the $L$ significance of the covering $\mathscr{C} \in \mathbf{C}$ by

$$
\operatorname{Sig}_{\mathbf{C}}^{L}(\mathscr{C})=\sum_{j=1}^{n} P l_{\mathbf{C} \backslash\{\mathscr{C}\}}^{L}\left(G_{j}\right)-\sum_{j=1}^{n} P l_{\mathbf{C}}^{L}\left(G_{j}\right) .
$$

By the definition of $F$ significance of a covering (or $L$ significance of a covering), the $\operatorname{Core}^{F}(\mathbf{C})\left(\right.$ or $\left.\operatorname{Core}^{L}(\mathbf{C})\right)$ can be characterized.

Proposition 3. Let $(U, C)$ be a covering information system. Then,

$$
\begin{aligned}
& \operatorname{Core}^{F}(\mathbf{C})=\left\{\mathscr{C} \in C \mid \operatorname{Sig}_{C}^{F}(\mathscr{C})>0\right\}, \\
& \operatorname{Core}^{L}(\mathbf{C})=\left\{\mathscr{C} \in \mathbf{C} \mid \operatorname{Sig}_{\mathbf{C}}^{L}(\mathscr{C})>0\right\} .
\end{aligned}
$$

Proof. For any $\mathscr{C} \in \operatorname{Core}^{F}(\mathbf{C}), \mathbf{C} \backslash\{\mathscr{C}\}$ is not an $F$ topological consistent set. Otherwise, there exists an $F$ topological reduct $\mathbf{B} \subseteq \mathbf{C} \backslash\{\mathscr{C}\}$. Then, $\mathscr{C} \notin \mathbf{B}$, which contradicts the fact $\mathscr{C} \in \operatorname{Core}^{F}(\mathrm{C})$. By Theorem 2, $\sum_{i=1}^{m} P l_{\mathrm{C} \backslash\{\mathscr{C}\}}^{F}\left(K_{i}\right)>1$. It follows that $\operatorname{Sig}_{\mathbf{C}}^{F}(\mathscr{C})>0$. Therefore, $\operatorname{Core}^{F}(\mathbf{C}) \subseteq$ $\left\{\mathscr{C} \in \mathrm{C} \mid \operatorname{Sig}_{\mathrm{C}}^{F}(\mathscr{C})>0\right\}$. Conversely, for any $\mathscr{C} \in\{\mathscr{C} \in \mathbf{C} \mid$ $\left.\operatorname{Sig}_{\mathrm{C}}^{F}(\mathscr{C})>0\right\}, \quad \operatorname{Sig}_{\mathrm{C}}^{F}(\mathscr{C})>0$. Hence, $\quad \operatorname{Sig}_{\mathrm{C}}^{F}(\mathscr{C})=\sum_{i=1}^{m}$ $P l_{\mathbf{C} \backslash\{\mathscr{C}\}}^{F}\left(K_{i}\right)-\sum_{i=1}^{m} P l_{\mathrm{C}}^{F}\left(K_{i}\right)>0$. Since $\sum_{i=1}^{m} P l_{\mathbf{C}}^{F}\left(K_{i}\right)=1$, $\sum_{i=1}^{m} P l_{\mathbf{C} \backslash\{\mathscr{C}\}}^{F}\left(K_{i}\right)>1$. By Theorem 2, C $\backslash\{\mathscr{C}\}$ is not an $F$ topological consistent set, which implies that $\mathbf{C} \backslash\{\mathscr{C}\}$ is not an $F$ topological reduct. Hence, $\mathscr{C}$ belongs to each $F$ topological reduct of C. It follows that $\mathscr{C} \in \operatorname{Core}^{F}(\mathrm{C})$. Then, $\left\{\mathscr{C} \in \mathbf{C} \mid \operatorname{Sig}_{\mathrm{C}}^{F}(\mathscr{C})>0\right\} \subseteq \operatorname{Core}^{F}(\mathbf{C})$.

Similarly, we can get $\operatorname{Core}^{L}(\mathbf{C})=\left\{\mathscr{C} \in \mathbf{C} \mid \operatorname{Sig}_{\mathbf{C}}^{L}(\mathscr{C})>0\right\}$.

From Proposition 3, the significance of each covering in the core of $\mathbf{C}$ is larger than zero. Now we present a concept of the significance of a covering $\mathscr{C} \in \mathbf{C} \backslash \mathbf{B}$ relative to the family of coverings $\mathbf{B}$.

Definition 10. Let $(U, \mathbf{C})$ be a covering information system, $\mathbf{B} \subseteq \mathbf{C}$. Define the $\mathrm{F}$ significance of $\mathscr{C} \in \mathbf{C} \backslash \mathbf{B}$ relative to $\mathbf{B}$ by

$$
\operatorname{Sig}_{\mathbf{B}}^{F}(\mathscr{C})=\sum_{i=1}^{m} P l_{\mathbf{B}}^{F}\left(K_{i}\right)-\sum_{i=1}^{m} P l_{\mathbf{B} \cup\{\mathbf{C}\}}^{F}\left(K_{i}\right) .
$$

Define the $L$ significance of $\mathscr{C} \in \mathbf{C} \backslash \mathbf{B}$ relative to $\mathbf{B}$ by

$$
\operatorname{Sig}_{\mathbf{B}}^{L}(\mathscr{C})=\sum_{j=1}^{n} P l_{\mathbf{B}}^{L}\left(G_{j}\right)-\sum_{j=1}^{m} P l_{\mathbf{B} \cup\{\mathbf{C}\}}^{L}\left(G_{j}\right) .
$$


Let $\sum_{i=1}^{m} P l_{\varnothing}^{F}\left(K_{i}\right)=m$ and $\sum_{j=1}^{n} P l_{\varnothing}^{L}\left(G_{j}\right)=n$. The relative significance $\operatorname{Sig}_{\mathbf{B}}^{F}(\mathscr{C})$ (or $\operatorname{Sig}_{\mathbf{B}}^{L}(\mathscr{C})$ ) can measure importance degree of the covering $\mathscr{C}$ relative to $\mathbf{B}$.

Now we design algorithms to find an $F$ topological reduct or an $\mathrm{L}$ topological reduct of the covering information system $(U, \mathbf{C})$.

The time complexity of Algorithms 1 and 2 is $O\left(|\mathbf{C}|^{3} \times|U|^{2}\right)$. In the following, an example is given to illustrate the mechanism of Algorithms 1 and 2.

Example 2. Continued from Example 1.

(1) Computing $F$ topological reducts: first, $F H_{\mathrm{C} \backslash\left\{\mathscr{C}_{1}\right\}}\left(K_{1}\right)=\left\{x_{1}, x_{2}\right\}, \quad F H_{\mathrm{C} \backslash\left\{\mathscr{C}_{1}\right\}}\left(K_{2}\right)=\left\{x_{3}, x_{4}\right\}$, and $\mathrm{FH}_{\mathbf{C}\left\{\mathscr{C}_{1}\right\}}\left(K_{3}\right)=\left\{x_{5}\right\}$. Thus, we get

$$
\begin{aligned}
\operatorname{Sig}_{\mathrm{C}}^{F}\left(\mathscr{C}_{1}\right) & =\sum_{i=1}^{3} P l_{\mathrm{C} \backslash\left\{\mathscr{C}_{1}\right\}}^{F}\left(K_{i}\right)-\sum_{i=1}^{3} P l_{\mathrm{C}}^{F}\left(K_{i}\right) \\
& =\left(\left(\frac{2}{5}\right)+\left(\frac{2}{5}\right)+\left(\frac{1}{5}\right)\right)-1=0 .
\end{aligned}
$$

By $\quad F H_{\mathbf{C} \backslash\left\{\mathscr{C}_{2}\right\}}\left(K_{1}\right)=\left\{x_{1}, x_{2}\right\}$,

$F H_{\mathrm{C} \backslash\left\{\mathscr{C}_{2}\right\}}\left(K_{2}\right)=\left\{x_{3}, x_{4}, x_{5}\right\}$, and

$F H_{\mathrm{C} \backslash\left\{\mathscr{C}_{2}\right\}}\left(K_{3}\right)=\left\{x_{4}, x_{5}\right\}$, we have

$\operatorname{Sig}_{\mathbf{C}}^{F}\left(\mathscr{C}_{2}\right)=\sum_{i=1}^{3} P l_{\mathbf{C} \backslash\left\{\mathscr{C}_{2}\right\}}^{F}\left(K_{i}\right)-\sum_{i=1}^{3} P l_{\mathbf{C}}^{F}\left(K_{i}\right)$

$$
=\left(\left(\frac{2}{5}\right)+\left(\frac{3}{5}\right)+\left(\frac{2}{5}\right)\right)-1=\left(\frac{2}{5}\right)>0 .
$$

Since $\quad F H_{\mathbf{C} \backslash\left\{\mathscr{C}_{3}\right\}}\left(K_{1}\right)=\left\{x_{1}, x_{2}, x_{3}\right\}$, $\mathrm{FH}_{\mathrm{C} \backslash\left\{\mathscr{C}_{3}\right\}}\left(K_{2}\right)=\left\{x_{2}, x_{3}, x_{4}\right\}, \quad$ and $F H_{\mathbf{C} \backslash\left\{\mathscr{C}_{3}\right\}}\left(K_{3}\right)=\left\{x_{5}\right\}$, we obtain

$$
\begin{aligned}
\operatorname{Sig}_{\mathrm{C}}^{1}\left(\mathscr{C}_{3}\right) & =\sum_{i=1}^{3} P l_{\mathrm{C} \backslash\left\{\mathscr{C}_{3}\right\}}^{F}\left(K_{i}\right)-\sum_{i=1}^{3} P l_{\mathrm{C}}^{F}\left(K_{i}\right) \\
& =\left(\left(\frac{3}{5}\right)+\left(\frac{3}{5}\right)+\left(\frac{1}{5}\right)\right)-1=\left(\frac{2}{5}\right)>0 .
\end{aligned}
$$

Hence, $\operatorname{Core}^{F}(\mathbf{C})=\left\{\mathscr{C}_{2}, \mathscr{C}_{3}\right\}$.

Second, since $\sum_{i=1}^{3} P l_{\text {Core }^{F}(\mathbf{C})}^{F}\left(K_{i}\right)=1, \operatorname{Core}^{F}(\mathbf{C})=$ $\left\{\mathscr{C}_{2}, \mathscr{C}_{3}\right\}$ is an $F$ topological reduct.

(2) Computing $L$ topological reducts: first, $L H_{\mathrm{C} \backslash\left\{\mathscr{C}_{1}\right\}}\left(G_{1}\right)=\left\{x_{1}, x_{2}\right\}, \quad L H_{\mathrm{C} \backslash\left\{\mathscr{C}_{1}\right\}}\left(G_{2}\right)=\left\{x_{3}\right\}$, $L H_{\mathrm{C} \backslash\left\{\mathscr{C}_{1}\right\}}\left(G_{3}\right)=\left\{x_{4}\right\}$, and $L H_{\mathrm{C} \backslash\left\{\mathscr{C}_{1}\right\}}\left(G_{4}\right)=\left\{x_{5}\right\}$; then,

$$
\begin{aligned}
\operatorname{Sig}_{\mathrm{C}}^{L}\left(\mathscr{C}_{1}\right) & =\sum_{j=1}^{4} P l_{\mathbf{C} \backslash\left\{\mathscr{C}_{1}\right\}}^{L}\left(G_{j}\right)-\sum_{j=1}^{4} P l_{\mathrm{C}}^{L}\left(G_{j}\right) \\
& =\left(\left(\frac{2}{5}\right)+\left(\frac{1}{5}\right)+\left(\frac{1}{5}\right)+\left(\frac{1}{5}\right)\right)-1=0 .
\end{aligned}
$$

By $\quad L H_{\mathrm{C} \backslash\left\{\mathscr{C}_{2}\right\}}\left(G_{1}\right)=\left\{x_{1}, x_{2}\right\}, \quad L H_{\mathrm{C} \backslash\left\{\mathscr{C}_{2}\right\}}\left(G_{2}\right)=$ $\left\{x_{3}, x_{4}\right\}, L H_{\mathrm{C} \backslash\left\{\mathscr{C}_{2}\right\}}\left(G_{3}\right)=\left\{x_{3}, x_{4}, x_{5}\right\}$, and $L H_{\mathrm{C} \backslash\left\{\mathscr{C}_{2}\right\}}$ $\left(G_{4}\right)=\left\{x_{4}, x_{5}\right\}$, we obtain

$$
\begin{aligned}
\operatorname{Sig}_{\mathrm{C}}^{L}\left(\mathscr{C}_{2}\right) & =\sum_{j=1}^{4} P l_{\mathrm{C} \backslash\left\{\mathscr{C}_{1}\right\}}^{L}\left(G_{j}\right)-\sum_{i=1}^{4} P l_{\mathrm{C}}^{L}\left(G_{j}\right) \\
& =\left(\left(\frac{2}{5}\right)+\left(\frac{2}{5}\right)+\left(\frac{3}{5}\right)+\left(\frac{2}{5}\right)\right)-1=\left(\frac{4}{5}\right)>0 .
\end{aligned}
$$

Since $L H_{\mathbf{C} \backslash\left\{\mathscr{C}_{3}\right\}}\left(G_{1}\right)=\left\{x_{1}, x_{2}\right\}, \quad L H_{\mathbf{C} \backslash\left\{\mathscr{C}_{3}\right\}}\left(G_{2}\right)=$ $\left\{x_{3}\right\}, L H_{\mathbf{C} \backslash\left\{\mathscr{C}_{3}\right\}}\left(G_{3}\right)=\left\{x_{4}\right\}$, and $L H_{\mathbf{C} \backslash\left\{\mathscr{C}_{3}\right\}}\left(G_{4}\right)=$ $\left\{x_{5}\right\}$, we have

$$
\begin{aligned}
\operatorname{Sig}_{\mathrm{C}}^{L}\left(\mathscr{C}_{3}\right) & =\sum_{j=1}^{4} P l_{\mathrm{C} \backslash\left\{\mathscr{C}_{1}\right\}}^{L}\left(G_{j}\right)-\sum_{i=1}^{4} P l_{\mathrm{C}}^{L}\left(G_{j}\right) \\
& =\left(\left(\frac{2}{5}\right)+\left(\frac{1}{5}\right)+\left(\frac{1}{5}\right)+\left(\frac{1}{5}\right)\right)-1=0 .
\end{aligned}
$$

Hence, $\operatorname{Core}^{L}(\mathbf{C})=\left\{\mathscr{C}_{2}\right\}$.

Second, it follows from $\sum_{j=1}^{4} P l_{\text {Core }^{L}(C)}^{L}\left(G_{j}\right)=$ $(10 / 5) \neq 1$ that $\operatorname{Core}^{L}(\mathbf{C})=\left\{\mathscr{C}_{2}\right\}$ is not an $L$ topological reduct.

Since

$$
\begin{aligned}
\operatorname{Sig}_{\operatorname{Core}^{L}(\mathbf{C})}^{L}\left(\mathscr{C}_{1}\right) & =\sum_{j=1}^{4} P l_{\left\{\mathscr{C}_{2}\right\}}^{L}\left(G_{j}\right)-\sum_{i=1}^{4} P l_{\left\{\mathscr{C}_{1}, \mathscr{C}_{2}\right\}}^{L}\left(G_{j}\right) \\
& =\left(\frac{10}{5}\right)-1=1, \\
\operatorname{Sig}_{\operatorname{Core}^{L}(\mathbf{C})}^{L}\left(\mathscr{C}_{3}\right) & =\sum_{j=1}^{4} P l_{\left\{\mathscr{C}_{2}\right\}}^{L}\left(G_{j}\right)-\sum_{i=1}^{4} P l_{\left\{\mathscr{C}_{2}, \mathscr{C}_{3}\right\}}^{L}\left(G_{j}\right) \\
& =\left(\frac{10}{5}\right)-1=1,
\end{aligned}
$$

let $\mathbf{B}=\operatorname{Core}^{L}(\mathbf{C}) \cup\left\{\mathscr{C}_{1}\right\}=\left\{\mathscr{C}_{1}, \mathscr{C}_{2}\right\}$. We get $\sum_{j=1}^{4} P l_{\mathbf{B}}^{L}\left(G_{j}\right)=1$; then, $\mathbf{B}=\left\{\mathscr{C}_{1}, \mathscr{C}_{2}\right\}$ is an $L$ topological reduct.

Similarly, we can obtain that $\left\{\mathscr{C}_{2}, \mathscr{C}_{3}\right\}$ is an $L$ topological reduct.

Therefore, $\operatorname{Core}^{L}(\mathbf{C})=\left\{\mathscr{C}_{2}\right\}$, and $\left\{\mathscr{C}_{1}, \mathscr{C}_{2}\right\}$ and $\left\{\mathscr{C}_{2}, \mathscr{C}_{3}\right\}$ are $L$ topological reducts.

\section{Comparing $L$ Topological Reduction with a Kind of Reduction in Covering Information Systems}

Chen et al. presented a definition of reduction in a covering information system [23].

Definition 11 (see [23]). Let $(U, \mathbf{C})$ be a covering information system. For any $\mathbf{B} \subseteq \mathbf{C}$, denote $\operatorname{Cov}(\mathbf{B})=$ $\left\{(x)_{\mathbf{B}} \mid x \in U\right\}$. If $\operatorname{Cov}(\mathbf{B})=\operatorname{Cov}(\mathbf{C})$ and for any $\mathscr{C} \in B$, $\operatorname{Cov}(\mathbf{B}) \neq \operatorname{Cov}(\mathbf{B}-\{\mathscr{C}\})$, then $\mathbf{B}$ is called a reduct of $(U, \mathbf{C})$. 
Example 3. Let $U$ and $\mathbf{C}$ be the same as those in Example 1. By Definition 11 and Table $1, \operatorname{Cov}(\mathbf{C})=\left\{\left\{x_{1}, x_{2}\right\}\right.$, $\left.\left\{x_{2}\right\},\left\{x_{3}\right\},\left\{x_{4}\right\},\left\{x_{5}\right\}\right\}, \operatorname{Cov}\left(\left\{\mathscr{C}_{1}, \mathscr{C}_{2}\right\}\right)=\operatorname{Cov}(\mathbf{C}), \operatorname{Cov}\left(\left\{\mathscr{C}_{1}\right.\right.$, $\left.\left.\mathscr{C}_{2}\right\}\right) \neq \operatorname{Cov}\left(\left\{\mathscr{C}_{1}\right\}\right)$, and $\operatorname{Cov}\left(\left\{\mathscr{C}_{1}, \mathscr{C}_{2}\right\}\right) \neq \operatorname{Cov}\left(\left\{\mathscr{C}_{2}\right\}\right)$. Then, $\left\{\mathscr{C}_{1}, \mathscr{C}_{2}\right\}$ is a reduct of $(U, \mathrm{C})$. Furthermore, $\left\{\mathscr{C}_{1}, \mathscr{C}_{2}\right\}$ is the only reduct of $(U, \mathbf{C})$.

Proposition 2. Let $(U, C)$ be a covering information system, $\mathbf{B} \subseteq \mathbf{C}$. If $\mathbf{B}$ is a reduct, then $\mathbf{B}$ is an L topological consistent set.

Proof. Since $\mathbf{B}$ is a reduct, by Definition $11,(x)_{\mathrm{C}}=(x)_{\mathrm{B}}$ for all $x \in U$. It follows that for any $X \subseteq U, L H_{\mathbf{C}}(X)=L H_{\mathbf{B}}(X)$. Thus, $\tau\left(L H_{\mathbf{C}}\right)=\tau\left(L H_{\mathbf{B}}\right)$, which implies that $\mathbf{B}$ is an $L$ topological consistent set.

Remark 2. (1) $F$ topological reducts of $(U, \mathbf{C})$ are not necessary correlated with the reducts of $(U, \mathbf{C})$.

From Example 1 and Example 3, we can know that the $F$ topological reduct of $(U, \mathbf{C})$ is $\left\{\mathscr{C}_{2}, \mathscr{C}_{3}\right\}$, and the reduct of $(U, \mathrm{C})$ is $\left\{\mathscr{C}_{1}, \mathscr{C}_{2}\right\}$.

(2) $L$ topological reduct of $(U, C)$ could not be a reduct of $(U, \mathbf{C})$.

For example, $\left\{\mathscr{C}_{2}, \mathscr{C}_{3}\right\}$ is an $L$ topological reduct of the covering information system $(U, C)$ in Example 1. However, $\left\{\mathscr{C}_{2}, \mathscr{C}_{3}\right\}$ is not a reduct of $(U, \mathbf{C})$.

\section{Conclusion}

In this paper, the $L$ topological reduction and the $F$ topological reduction of covering information systems have been characterized by the belief and plausibility functions from the evidence theory. The topological spaces by the two pairs of covering approximation operators in covering information systems are pseudo-discrete, which deduce partitions. Then, using plausibility function values of sets in the partitions, the definitions of significance and relative significance of coverings in covering information systems have been also developed. Hence, topological reduction algorithms based on the evidence theory have been proposed in covering information systems, and an example has been adopted to illustrate the validity of the algorithms. We have also compared the $L$ topological reduction with a kind of reduction proposed in [23].

\section{Data Availability}

The underlying data supporting the results of this study are available from the corresponding author upon request.

\section{Conflicts of Interest}

The authors declare that they have no conflicts of interest.

\section{Acknowledgments}

This study was supported by Grants from the National Natural Science Foundation of China (nos. 11701258 and
11871259) and the Natural Science Foundation of Fujian (nos. 2019J01749, 2020J01801, and 2020J02043).

\section{References}

[1] Z. A. Pawlak, "Rough sets," International Journal of Computer \& Information Sciences, vol. 11, no. 5, pp. 341-356, 1982.

[2] Z. Bonikowski, E. Bryniarski, and U. Wybraniec-Skardowska, "Extensions and intentions in the rough set theory," Information Sciences, vol. 107, no. 1-4, pp. 149-167, 1998.

[3] E Bryniarski, "A calculus of rough sets of the first order," Bulletin of the Polish Academy of Sciences, vol. 36, no. 16, pp. 71-77, 1989.

[4] A. A. Estaji, M. Vatandoost, and R. Pourkhandani, "Fixed points of covering upper and lower approximation operators," Soft Computing, vol. 23, no. 22, pp. 11447-11460, 2019.

[5] B. Huang, H. Li, G. Feng, and C. Guo, "Intuitionistic fuzzy $\beta$ -covering-based rough sets," Artificial Intelligence Review, vol. 53, no. 4, pp. 2841-2873, 2020.

[6] G. Liu, "The relationship among different covering approximations," Information Sciences, vol. 250, pp. 178-183, 2013.

[7] J. A Pomykala, "Approximation operations in approximation space," Bulletin of the Polish Academy of Sciences, vol. 35, no. 9-10, pp. 653-662, 1987.

[8] K Qin, Y Gao, and Z Pei, "On covering rough sets," in Proceedings of the the Second International Conference on Rough Sets and Knowledge Technology (RSKT 2007), vol. 4481, pp. 34-41, Toronto, Canada, May 2007.

[9] M. Restrepo, C. Cornelis, and J. Gómez, "Partial order relation for approximation operators in covering based rough sets," Information Sciences, vol. 284, pp. 44-59, 2014.

[10] M. Restrepo, C. Cornelis, and J. Gómez, "Duality, conjugacy and adjointness of approximation operators in coveringbased rough sets," International Journal of Approximate Reasoning, vol. 55, no. 1, pp. 469-485, 2014.

[11] L. Wang, X. Yang, J. Yang, and C. Wu, "Relationships among generalized rough sets in six coverings and pure reflexive neighborhood system," Information Sciences, vol. 207, pp. 66-78, 2012.

[12] J. Wang and X. Zhang, "Two types of single valued neutrosophic covering rough sets and an application to decision making," Symmetry, vol. 10, no. 12, p. 710, 2018.

[13] J. Wang and X. Zhang, "Two types of intuitionistic fuzzy covering rough sets and an application to multiple criteria group decision making," Symmetry, vol. 10, no. 10, p. 462, 2018.

[14] Z. Wang, X. Zhang, and J. Deng, "The uncertainty measures for covering rough set models," Soft Computing, vol. 24, no. 16, pp. 11909-11929, 2020.

[15] W.-H. Xu and W.-X. Zhang, "Measuring roughness of generalized rough sets induced by a covering," Fuzzy Sets and Systems, vol. 158, no. 22, pp. 2443-2455, 2007.

[16] Y. Yao and B. Yao, "Covering based rough set approximations," Information Sciences, vol. 200, pp. 91-107, 2012.

[17] Z. Yun, X. Ge, and X. Bai, "Axiomatization and conditions for neighborhoods in a covering to form a partition," Information Sciences, vol. 181, no. 9, pp. 1735-1740, 2011.

[18] W Żakowski, “Approximations in the space $(U, \Pi)$," Demonstratio Mathematica, vol. 16, pp. 761-769, 1983.

[19] Y.-L. Zhang, C.-Q. Li, and J. Li, "On characterizations of a pair of covering-based approximation operators," Soft Computing, vol. 23, no. 12, pp. 3965-3972, 2019. 
[20] Z. Zhao, "On some types of covering rough sets from topological points of view," International Journal of Approximate Reasoning, vol. 68, pp. 1-14, 2016.

[21] W. Zhu and F.-Y. Wang, "On three types of covering-based rough sets," IEEE Transactions on Knowledge and Data Engineering, vol. 19, no. 8, pp. 1131-1144, 2007.

[22] M. Cai, G. Lang, H. Fujita, Z. Li, and T. Yang, "Incremental approaches to updating reducts under dynamic covering granularity," Knowledge-Based Systems, vol. 172, pp. 130-140, 2019.

[23] D. Chen, W. Li, X. Zhang, and S. Kwong, "Evidence-theorybased numerical algorithms of attribute reduction with neighborhood-covering rough sets," International Journal of Approximate Reasoning, vol. 55, no. 3, pp. 908-923, 2014.

[24] D. Chen, C. Wang, and Q. Hu, "A new approach to attribute reduction of consistent and inconsistent covering decision systems with covering rough sets," Information Sciences, vol. 177, pp. 3500-3518, 2007.

[25] J. Chen, Y. Lin, G. Lin, J. Li, and Y. Zhang, "Attribute reduction of covering decision systems by hypergraph model," Knowledge-Based Systems, vol. 118, pp. 93-104, 2017.

[26] G. Lang, D. Miao, T. Yang, and M. Cai, "Knowledge reduction of dynamic covering decision information systems when varying covering cardinalities," Information Sciences, vol. 346347, pp. 236-260, 2016.

[27] F. Li and Y. Yin, "Approaches to knowledge reduction of covering decision systems based on information theory," Information Sciences, vol. 179, no. 11, pp. 1694-1704, 2009.

[28] A. Tan, J. Li, Y. Lin, and G. Lin, "Matrix-based set approximations and reductions in covering decision information systems," International Journal of Approximate Reasoning, vol. 59, pp. 68-80, 2015.

[29] E. C. C. Tsang, C. Degang, and D. S. Yeung, "Approximations and reducts with covering generalized rough sets," Computers \& Mathematics with Applications, vol. 56, no. 1, pp. 279-289, 2008.

[30] C. Wang, Q. He, D. Chen, and Q. Hu, "A novel method for attribute reduction of covering decision systems," Information Sciences, vol. 254, pp. 181-196, 2014.

[31] C. Wang, M. Shao, B. Sun, and Q. Hu, "An improved attribute reduction scheme with covering based rough sets," Applied Soft Computing, vol. 26, pp. 235-243, 2015.

[32] T. Yang, Q. Li, and B. Zhou, "Related family: a new method for attribute reduction of covering information systems," Information Sciences, vol. 228, pp. 175-191, 2013.

[33] X. Bian, P. Wang, Z. Yu, X. Bai, and B. Chen, "Characterizations of coverings for upper approximation operators being closure operators," Information Sciences, vol. 314, pp. 41-54, 2015.

[34] B. Chen, "Topological structures on covering-based rough sets," Inform Japan, vol. 16, no. 6, pp. 3335-3342, 2013.

[35] X. Ge, X. Bai, and Z. Yun, "Topological characterizations of covering for special covering-based upper approximation operators," Information Sciences, vol. 204, pp. 70-81, 2012.

[36] S.-E. Han, "Marcus-Wyse topological rough sets and their applications," International Journal of Approximate Reasoning, vol. 106, pp. 214-227, 2019.

[37] M. Restrepo and J. Gómez, "Topological properties for approximation operators in covering based rough sets," Lecture Notes in Computer Science, vol. 9437, no. 302-9743, pp. 112-123, 2015.

[38] X. Wang and L. Ma, "Study on covering rough sets with topological methods," CAAI Transactions on Intelligence Technology, vol. 4, no. 3, pp. 129-134, 2019.
[39] Z. Zhao, "Maps between covering approximation spaces and the product space of two covering approximation spaces," International Journal of Approximate Reasoning, vol. 115, pp. 144-156, 2019.

[40] Y. Zhang and J. Li, "The reduction in a family of coverings producing a topology," Journal of Mathematics, vol. 31, no. 3, pp. 495-501, 2011, in Chinese.

[41] A. P. Dempster, "Upper and lower probabilities induced by a multivalued mapping," The Annals of Mathematical Statistics, vol. 38, no. 2, pp. 325-339, 1967.

[42] G. Shafer, A Mathematical Theory of Evidence, Princeton University Press, Princeton, NJ, USA, 1976.

[43] X. Che, J. Mi, and D. Chen, "Information fusion and numerical characterization of a multi-source information system," Knowledge-Based Systems, vol. 145, pp. 121-133, 2018.

[44] D. Chen, X. Zhang, and W. Li, "On measurements of covering rough sets based on granules and evidence theory," Information Sciences, vol. 317, pp. 329-348, 2015.

[45] A. Tan, W.-Z. Wu, and Y. Tao, "A unified framework for characterizing rough sets with evidence theory in various approximation spaces," Information Sciences, vol. 454-455, pp. 144-160, 2018.

[46] X. You, J. Li, and H. Wang, "Relative reduction of neighborhood-covering pessimistic multigranulation rough set based on evidence theory," Information, vol. 10, no. 11, p. 334, 2019.

[47] Y. Zhang, C. Li, and Q. Xu, "Evidence-theory-based numerical characterization of attribute reduction in covering decision information system," Journal of Nanjing University of Aeronautics \& Astronautics, vol. 51, no. 5, pp. 599-608, 2019, in Chinese.

[48] Y. Zhang and C. Li, "Attribute reduction of covering decision information system based on evidence theory," Pattern Recognition and Artificial Intelligence, vol. 31, no. 9, pp. 797-808, 2018, in Chinese.

[49] R. Engelking, General Topology, PWN, Warszawa, Poland, 1977.

[50] E. Cěch, Topological Spaces, Wiley, New York, NY, USA, 1966.

[51] Y. Yao, "Relational interpretations of neighborhood operators and rough set approximation operators," Information Sciences, vol. 111, no. 1-4, pp. 239-259, 1998.

[52] Y. Yao, "On generalizing rough set theory," in Proceedings of the the 9th International Conference on Rough Sets, Fuzzy Sets, Data Mining, and Granular Computing (RSFDGrc 2003), vol. 2639, Chongqing, China, May 2003.

[53] Y. Zhang, J. Li, and W. Wu, "On axiomatic characterizations of three pairs of covering-based approximation operators," Information Sciences, vol. 180, pp. 174-187, 2010.

[54] Y.-L. Zhang and C.-Q. Li, "Topological structures of a type of granule based covering rough sets," Filomat, vol. 32, no. 9, pp. 3129-3141, 2018.

[55] J. W Tukey, Covergence and Uniformity in Topology, Ann Math Studies, 2, Princeton University Press, Princeton, NJ, USA, 1940. 